\title{
Conservation of the largest cervid of South America: interactions between people and the Vulnerable marsh deer Blastocerus dichotomus
}

\author{
M. Eugenia Iezzi, Natalia G. Fracassi and Javier A. Pereira
}

\begin{abstract}
Wild ungulates, and particularly deer, can cause severe damage to commercial plantations, resulting in reduced tolerance of their presence by forestry producers. The marsh deer Blastocerus dichotomus, categorized as Vulnerable on the IUCN Red List, is declining throughout South America. A population of c. 500 individuals survive within a matrix of commercial plantations in the lower delta of the Paraná River, the southernmost stronghold for the species. Local forestry producers usually report that damage to plantations is attributable to marsh deer, thus justifying persecution of the species. Seventy-six forestry producers (representing c. $33 \%$ of the total plantation area of the lower delta) were interviewed using a semi-structured questionnaire to assess perceived levels of tree damage, associated economic losses, and attitudes towards the deer. Simultaneously, plantation stands were surveyed to quantify the actual tree damage caused by this ungulate. Seventy-six percent of producers reported damage to trees by deer (i.e. browsing, fraying caused by antler rubbing) but most of them perceived low levels of damage per property (median $<0.2 \%$ ), with negligible economic effects. However, $5 \%$ of producers (all of them with $\leq 2 \mathrm{~km}^{2}$ in production, usually family enterprises) perceived high levels of damage and economic losses, and supported deer hunting as a management option. Field surveys indicated that damage caused by deer could be more severe than perceived by producers, although spatially confined within the landscape. Monitoring of damage perception by forestry producers, and compensation schemes to assist small producers are necessary for adequate management of this threatened marsh deer population.
\end{abstract}

Keywords Argentina, Blastocerus dichotomus, forestry, human-wildlife interactions, interviews, Paraná River delta, perceived vs actual damage, Salicaceae

\footnotetext{
M. Eugenia Iezzi Facultad de Ciencias Exactas y Naturales, Universidad de Buenos Aires, Buenos Aires, Argentina, and Instituto de Biología Subtropical, Universidad Nacional de Misiones-Consejo Nacional de Investigaciones Científicas y Técnicas, Puerto Iguazú, Misiones, Argentina

Natalia G. Fracassi Instituto Nacional de Tecnología Agropecuaria, Estación Experimental Agropecuaria 'Delta del Paraná', Campana, Provincia de Buenos Aires, Argentina

Javier A. Pereira (Corresponding author) Museo Argentino de Ciencias Naturales 'Bernardino Rivadavia'-Consejo Nacional de Investigaciones Científicas y Técnicas, Av. Ángel Gallardo 470 (C1405DJR), Ciudad de Buenos Aires, Argentina. E-mail javipereira@yahoo.com

Received 29 January 2017. Revision requested 27 March 2017.

Accepted 12 May 2017. First published online 27 July 2017.
}

\section{Introduction}

Wildlife damage to agriculture and forestry is a serious concern among producers globally (Gill, 1992; Conover, 1998). This situation has important implications for the sustainability of these economic activities and also for wildlife conservation (Schonewald-Cox et al., 1992). Wild ungulates, and particularly deer, can cause severe damage to crops (e.g. Richer et al., 2005) and tree plantations (e.g. Ward et al., 2004; Takatsuki, 2009); in the USA, for example, an estimated loss of USD 100 million in agricultural production per year has been attributed to deer (Conover, 1997).

Deer damage trees mainly during feeding (i.e. selective browsing of leaves, fruits or bark) or antler rubbing (Gill, 1992). Usually these interactions do not affect tree survival (Russell et al., 2001) but tree diameter and growth can decrease if deer pressure is high, resulting in economic losses (Ward et al., 2004). Producers are willing to incur some damage (Siemer \& Decker, 1996) but if they perceive that the amount of damage is high, they may take whatever action they deem necessary to alleviate these losses. Producers can thus have a significant impact on the conservation status of deer populations.

The marsh deer Blastocerus dichotomus is the largest (up to $140 \mathrm{~kg}$ of body mass) deer of South America, ranging from southern Amazonia to Argentina (Duarte \& González, 2010). Although historically the species occupied a wide range of habitats along the major river basins in South America, it has experienced a $65 \%$ reduction (Weber \& González, 2003) and is categorized as Vulnerable on the IUCN Red List (Duarte et al., 2016). The delta of the Paraná River shelters the southernmost population of marsh deer (Varela, 2003), comprising c. 500 individuals (Lartigau et al., 2012). This population is genetically different from other populations of the species (Márquez et al., 2006), which suggests that it should be considered a distinctive management unit.

The majority of marsh deer in the delta of the Paraná River occur near or within the largest area of commercial plantations of Salicaceae in Argentina (Varela, 2003; Fracassi \& Somma, 2010). According to local forestry producers the deer cause damage of varying extent and severity to these plantations, thus justifying persecution of the deer (D'Alessio et al., 2006). Recategorization of the conservation status of this population as Endangered has been proposed because of retaliatory killing, poaching, habitat loss, and predation by dogs (Lartigau et al., 2012). 
An assessment of the interactions between the marsh deer and commercial forestry producers of this wetland is needed, focusing on an accurate evaluation of damage, actual vs perceived production losses, and attitudes of producers towards the deer. Wildlife managers require this information to be effective in communicating with producers, for understanding the impact of marsh deer on local economies, and for planning the conservation of the species. In this context, our objectives were (1) to assess and characterize the perceived level of tree damage caused by deer, and economic losses in plantations of the delta of the Paraná River, (2) to determine attitudes of local producers towards the marsh deer, and (3) to quantify the extent and characteristics of actual tree damage caused by the marsh deer by sampling damage in plantation stands.

\section{Study area}

The lower delta of the Paraná River (c. 2,700 km², hereafter lower delta, Fig. 1), in Argentina, has typical deltaic morphology (Kandus \& Malvárez, 2004). The islands have a central area dominated by freshwater marshes, surrounded by a peripheral levee covered by riparian forests. Commercial plantation of poplar Populus spp. and willow Salix spp. is the main economic activity in the region, occupying c. $840 \mathrm{~km}^{2}$ (Fracassi et al., 2014). Water management is practised to avoid prolonged waterlogged conditions in plantations, including the construction of drainage channels and polders to protect trees from floodwaters. Wicker Salix viminalis is planted by small producers (with $\leq 2 \mathrm{~km}^{2}$ in production), whereas larger producers and forestry companies (with $>10 \mathrm{~km}^{2}$ in production) are diversifying by raising livestock under silvopastoral systems. New trees (0.5-3 m height) are planted during July-August and sprout during September-October (Borodowski \& Suárez, 2004). Poplar is harvested at 10-16 years, and willow at 8-12 years (Borodowski \& Suárez, 2004), whereas wicker is harvested annually before sprouting (during June-August) from the first year and up to 10 years (Olemberg \& Barán, 2016).

\section{Methods}

\section{Field interviews}

To evaluate forestry producers' perceptions of and attitudes towards damage caused by marsh deer in commercial plantations, we conducted semi-structured interviews (following methods described in Newing, 2011) with 76 small, medium and large forestry producers, whose properties comprised c. $33 \%$ of the total plantation area of the lower delta. Damage was considered to mean the removal of tissue (leaves, bark, shoots or buds) from a tree, without necessarily implying the death of the tree. Interviews were conducted on each property, in the frame of a friendly talk, during September 2012-March 2013. Participants were selected with the assistance of members of Instituto Nacional de Tecnología Agropecuaria (National Institute of Agricultural Technology), balancing producer types and geographical representation.

Four subjects were explored: (1) characteristics of the property and plantation management practices; (2) marsh deer presence and perceived abundance; (3) producers' perceptions about tree damage caused by deer, and associated economic losses; and (4) attitudes towards the deer, including the application of preventive measures to avoid tree damage (Table 1). Answers were converted into categorical, nominal or ordinal variables, except the estimated percentage of plants damaged by deer, which was considered to be a continuous quantitative variable. Relationships between variables were analysed using Spearman correlations. As several variables were associated, multivariate tests were not performed. Statistical analyses were conducted using SPSS 15.o (IBM, Armonk, USA), and differences were considered significant when $\mathrm{P}<0.05$.

\section{Field survey of actual damage}

To characterize and quantify actual damage to plantations caused by deer, surveys of damage were conducted on willow and poplar plantations at 22 properties where the owners were also interviewed. These properties were chosen based on accessibility and the willingness of the owner to collaborate with this research. Surveys were conducted during September 2012-March 2013, during or immediately after the plant growing season (i.e. the period with the highest level of damage, according to preliminary contacts with producers). On each property, plots of young trees $(<4$ years old) were surveyed; adult tree plots were not included because, according to preliminary interviews, they are not affected by marsh deer. We surveyed 1-5 plots per property, depending on the size of the property. Surveyed plots were at least $2 \mathrm{~km}$ apart, to be considered independent. Overall, 39 plots were surveyed, 16 of willow and 23 of poplar. Two sampling designs were followed: (1) if the producer was aware of damage caused by deer in the plantation, surveys were focused on these particular damaged plots, considering damage as maximum ('maximum damage' plots; $\mathrm{n}=15$ ); or (2) if the producer was not aware of the existence of damage, plots were selected randomly for surveying ('random damage' plots; $n=24$ ). At each sampling plot, two researchers with knowledge of patterns of damage by deer walked 2-6 line transects placed at random, looking for trees with signs of damage caused by marsh deer. The number and length of transects depended on plot size, accessibility, and tree spacing (e.g. $3 \times 3 \mathrm{~m}, 5 \times 5 \mathrm{~m})$. Transects were $35-3,470 \mathrm{~m}$ in length, and 18-1,802 trees were surveyed per plot (328 trees per plot, on average); in total, 17,673 trees were 


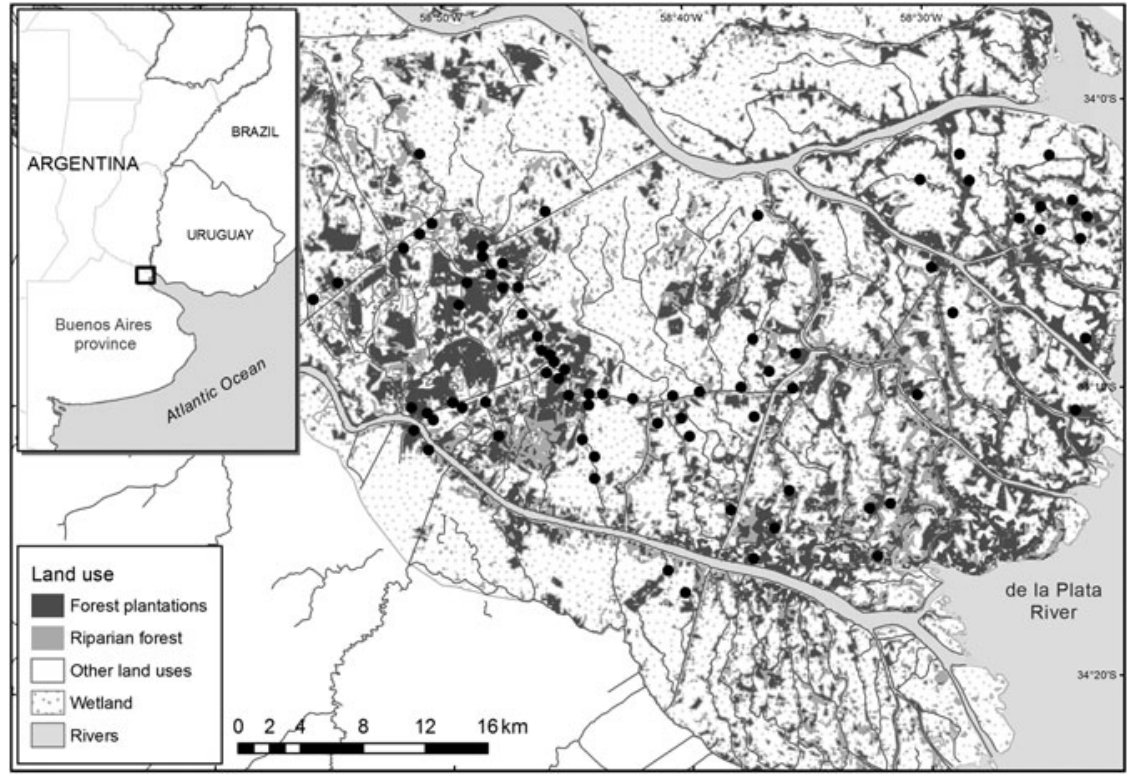

FIG. 1 Locations of plantations in the lower delta of the Paraná River, Argentina, where surveys were conducted to assess perceived and actual damage caused by marsh deer Blastocerus dichotomus. examined. We calculated the percentage of damaged plants per plot, discriminating between types of damage (feeding or antler rubbing). Understorey vegetation at each plot was assigned a value of $0-3$, depending on coverage $(0,<10 \%$; $1,10-30 \% ; 2,30-60 \% ; 3,>60 \%)$. A Kruskal-Wallis test was used to evaluate differences between random damage and maximum damage plots, between damage in poplar vs willow plots, and between actual vs perceived damage attributed to deer. Relationships between the percentage of damage and understorey vegetation coverage were analysed using Spearman correlations. Statistical analyses were conducted using InfoStat (Agricultural College of the National University of Córdoba, Argentina), and differences were considered significant when $\mathrm{P}<0.05$.

\section{Results}

Perception and attitudes regarding damage caused by marsh deer

Eighty-eight percent of the respondents $(n=67)$ reported marsh deer presence on their lands; $76 \%$ of these (36 small, 12 medium, and three large producers) recorded damage by marsh deer at the time of this survey or in the recent past (i.e. within the previous 2 years). Damage varied among plant species; fraying caused by antler rubbing was the predominant problem reported for poplar trees, occurring on plants 13 years old with trunk diameter of $2-6 \mathrm{~cm}$. Browsing on buds and leaves was the most reported problem for willow trees, and the only damage reported for wicker plants (Fig. 2).

Producers affirmed that damage by deer caused tree losses ( $76 \%$ of interviewees) and decreases in productivity ( $80 \%$ of interviewees), emphasizing a higher level of damage in willow or wicker plantations than in poplar plantations
(Table 2). Most producers perceived a low percentage of damaged trees per property (median value $<0.2 \%$; Table 2 ), with 'null' or 'irrelevant/non important' effects on their economies. However, $19 \%$ of interviewees $(n=14)$ reported mean damage levels $>10 \%$, always in willow or wicker plantations; only five (small) producers translated these damages into 'considerable' or 'severe/untenable' economic losses. Such heterogeneous positions regarding the economic impact led to a non-significant correlation between the percentage of perceived damage and the associated economic loss $\left(R_{\mathrm{s}}=0.29, \mathrm{P}=0.065\right)$.

A positive correlation between the estimated percentage of damage and the perceived abundance of deer was found $\left(R_{\mathrm{s}}=0.5, \mathrm{P}=0.0004\right)$. The majority of producers $(61 \%)$ believed that marsh deer abundance had increased over the previous 10 years, and c. $50 \%(n=36)$ considered it necessary to prevent damage by deer to avoid increasing losses. Some producers $(69 \%)$ felt that the implementation of compensatory measures (e.g. financial assistance) should be carried out by a governmental institution, and $21 \%$ of respondents had themselves taken at least one measure to prevent damage by deer. These measures were wire fencing (successful for four of five producers who employed it), scaring the deer with dogs or shotguns (six of nine), and deer hunting (four of nine). Electric fencing, used in the region to manage cattle, was reported to be ineffective by seven of eight producers, as marsh deer can jump across the electric lines.

\section{Quantification of actual damage}

Plots of maximum damage had a significantly higher percentage of damaged trees than plots of random damage (Kruskal-Wallis: $H=4.86, \quad \mathrm{P}=0.025$ for poplar, and 
TABLE 1 Questionnaire used to elicit information about management practices, presence and perceived abundance of the marsh deer Blastocerus dichotomus, perceptions about damage to trees by deer, and attitudes towards the deer in the lower delta of the Paraná River, Argentina (Fig. 1).

Vyariable
Response options
(a) Small $\left(\leq 2 \mathrm{~km}^{2}\right.$ in production)
(b) Medium $\left(>2-10 \mathrm{~km}^{2}\right.$ in production)
(c) Large $\left(>10 \mathrm{~km}^{2}\right.$ in production)

Species planted

(a) Willow (Salix spp.)

(b) Poplar (Populus spp.)

(c) Wicker (Salix viminalis)

Occurrence of marsh deer in the plantation

(a) Yes

(b) No

(c) Unknown

Current abundance of marsh deer in the plantation
(a) None
(b) Low (up to 3 individuals)
(c) Medium (4-8 individuals)
(d) High ( $>8$ individuals)
(e) Unknown

Current vs historical abundance of marsh deer in the plantation

Damage to commercial plants by marsh deer

Type of damage

Consequences of damage

Estimated \% of plants damaged by deer

Economic losses caused by deer

Is it necessary to prevent damage by deer?

Preventive, compensatory or retaliatory measures employed (or potentially useful) to avoid tree damage or economic losses attributable to marsh deer (a) More abundant now than 10 years ago

(b) More abundant 10 years ago than now

(c) Equally abundant now \& 10 years ago
(a) Yes
(b) No
(c) Unknown

(a) Fraying caused by antler rubbing

(b) Browsing on buds \& leaves

(c) Trunk or branches broken

(d) Other/unknown
(a) No effect
(b) Plant losses
(c) Decreases in productivity
(d) Other/unknown

Number (continuous variable)
(a) Null
(b) Irrelevant/non important
(c) Considerable
(d) Severe/untenable
(a) Yes
(b) No
(c) No opinion
(a) No action
(b) Wire or electric fencing
(c) Deer scaring
(d) Hunting problem deer
(e) Require economic assistance
(f) Other

$H=2.82, \mathrm{P}=0.014$ for willow; Table 2). The most frequent type of damage to willow plants was browsed leaves, found in $81 \%$ of willow plots; a few trees $(<4$ per plot $)$ with signs of fraying were found in five of 16 willow plots sampled. In contrast, fraying was the dominant type of damage among poplar plants, found in $73 \%$ of poplar plots; trees with browsed leaves ( $<3$ per plot) were found in only three of 23 poplar plots sampled. 


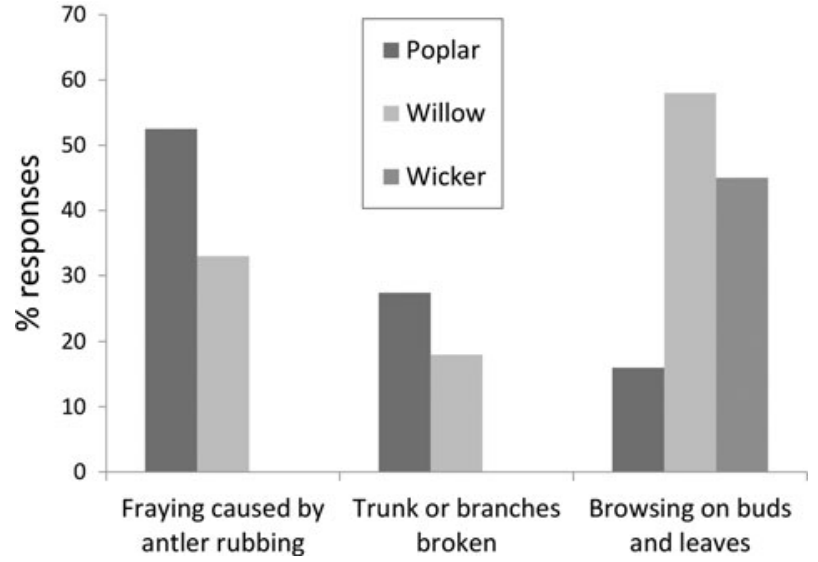

FIG. 2 Percentage of interviewees that reported various types of damage caused by marsh deer to poplar Populus spp., willow Salix spp. and wicker plants Salix viminalis in plantations in the lower delta of the Paraná River, Argentina (Fig. 1).

Considering only random samplings, willow plots had a significantly higher percentage of damaged trees than poplar plots (Kruskal-Wallis: $H=4.86, \mathrm{P}=0.0256$; Table 2), whereas the difference was not significant when comparing only maximum damage plots (Kruskal-Wallis: $H=5.36$, $\mathrm{P}=0.1206$; Table 2). The mean damage was positively correlated with understorey coverage in maximum damage plots of both poplar $\left(R_{\mathrm{s}}=0.9, \mathrm{P}=0.006\right)$ and willow $\left(R_{\mathrm{s}}=0.76\right.$, $\mathrm{P}=0.049)$, but this pattern was not observed in random damage plots of either poplar $\left(R_{\mathrm{s}}=-0.12, \mathrm{P}=0.660\right)$ or willow $\left(R_{\mathrm{s}}=-0.48, \mathrm{P}=0.230\right)$. There were no significant differences between the damage perceived by producers and the actual damage estimated through field sampling in random damage plots $(H=0.75, \mathrm{P}=0.36$ for poplar, and $H=2.03, \mathrm{P}=0.14$ for willow). However, the perceived damage was significantly lower than the actual damage estimated in maximum damage plots $(H=5.61, \mathrm{P}=0.012$ for poplar, and $H=11.1, \mathrm{P}<0.001$ for willow; Table 2).

\section{Discussion}

This is the first study to evaluate human-marsh deer interactions that integrates the perceptions of forestry producers with an estimation of the actual damage caused by the deer. According to producers, the marsh deer is widely present in commercial plantations of poplar and willow in the lower delta of the Paraná River, and although they were aware of tree damage caused by deer, these losses did not have a significant economic impact in most cases. However, a few small producers perceived high levels of damage and economic losses, and supported deer hunting as a management option. Field surveys showed that damage by deer could be more severe than perceived by most producers, although spatially confined within the landscape.
TABle 2 Estimated percentage of poplar Populus spp., willow Salix spp. and wicker Salix viminalis plants damaged by marsh deer, based on interviews and field surveys (considering plots with maximum damage and with random damage) in the lower delta of the Paraná River, Argentina (Fig. 1).

\begin{tabular}{|c|c|c|c|c|c|c|}
\hline \multirow{2}{*}{$\begin{array}{l}\text { Plant } \\
\text { species }\end{array}$} & \multirow{2}{*}{$\begin{array}{l}\text { Source of } \\
\text { estimation }\end{array}$} & \multirow[b]{2}{*}{$\mathrm{N}$} & \multicolumn{4}{|c|}{ Percentage of plants damaged } \\
\hline & & & Mean \pm SD & Min. & Max & Median \\
\hline \multirow[t]{3}{*}{ Poplar } & Interviews & 63 & $4.4 \pm 11.6$ & 0 & 50 & 0.01 \\
\hline & $\begin{array}{l}\text { Field survey } \\
\text { (random) }\end{array}$ & 16 & $1.5 \pm 2.2$ & 0 & 8 & 0.72 \\
\hline & $\begin{array}{l}\text { Field survey } \\
\text { (maximum) }\end{array}$ & 7 & $16.3 \pm 26.0$ & 0 & 21 & 4.50 \\
\hline \multirow[t]{3}{*}{ Willow } & Interviews & 49 & $9.4 \pm 18.3$ & 0 & 75 & 0.18 \\
\hline & $\begin{array}{l}\text { Field survey } \\
\text { (random) }\end{array}$ & 8 & $7.9 \pm 7.6$ & 1 & 72 & 5.91 \\
\hline & $\begin{array}{l}\text { Field survey } \\
\text { (maximum) }\end{array}$ & 8 & $42.2 \pm 32.2$ & 2 & 100 & 43.73 \\
\hline Wicker & Interviews & 17 & $13.7 \pm 27.1$ & 0 & 80 & 0 \\
\hline
\end{tabular}

\section{Actual vs perceived damage}

Bark stripping as a result of fraying was the predominant type of damage in poplar plantations, whereas the consumption of green sprouts, leaves and buds was predominant in willow and wicker plantations. Browsing does not imply the death of the plant but can diminish productivity (e.g. Russell et al., 2001; Ward et al., 2004). In the case of wicker, browsing usually leads to multi-stem plants, which are unsuitable for commercial use. A comprehensive economic assessment of the impacts (e.g. changes in wood quality, grow rates or productivity) of marsh deer on various commercial plant species would provide valuable information to support management decisions and consequently assist those producers who report damage.

Poplar and willow are planted by all types of producers but wicker is planted almost exclusively by small producers, usually family groups under the minimum forestry economic unit (Borodowski \& Suárez, 2004). Wicker plantations cover small areas, and if damage is spatially aggregated within a stand the impact per hectare (and the associated economic loss) could be significant. On the contrary, medium and large producers have better financial situations and larger plantations (some certified by the Forest Stewardship Council or the International Organization for Standardization) and are thus better able to cope with tree damage. As a result, small producers are potentially more likely to develop negative attitudes and behaviours towards marsh deer.

The positive correlation between perceived percentage of damage and perceived abundance of deer may be a result of the higher abundance (or activity) of marsh deer in the most damaged plots. Damage caused by deer in agricultural fields or plantations in other regions has been shown to be correlated with deer density (e.g. Putman et al., 2011). However, a 
perception bias may yield an alternative explanation. Local producers who had experienced damage by deer in the past tended to hold negative attitudes towards deer (authors, pers. obs.). Consequently, producers who had experienced high levels of damage in the past still reported damage in the present, even if they were unaware of the actual damage level or the density of deer on their property. This type of response has also been reported for other species in other productive areas (e.g. Campbell-Smith et al., 2010; Dressel et al., 2015; Caruso et al., 2017).

\section{Management implications, mitigation actions and conservation measures}

Wire fencing was the most effective measure reported by (a low number of) producers to prevent damage by marsh deer. Although fencing is a relatively low-cost measure and is widely used to avoid damage by deer (e.g. VerCauteren et al., 2006), only small areas can be protected in this way. Wicker shrubs are coppiced annually in the lower delta wetland to encourage production of long flexible shoots, and the same plants aggregated in small plots $(<1-11$ ha; mean $=1.68$ ha $)$ are used year after year (Olemberg \& Barán, 2016). Thus, fencing is an adequate strategy for the long-term protection of wicker plots. In addition, warning dogs are used to keep deer away from these plantations. The use of commercial repellents for reducing deer damage has not been tested in the lower delta, even though this practice has been reported to prevent damage by deer to forest plantations in other countries (Ward \& Williams, 2010).

In contrast, willow and poplar plantations are developed over much larger scales, and although half of interviewees considered it necessary to prevent damage by deer, only a small number of producers reported engaging in deer hunting for this purpose. Hunting is widely used to manage overabundant or lower-concern deer species (McShea, 2012) but its use on this threatened marsh deer population is illegal. However, practices such as this become popular when producers perceive that authorities are indifferent to their claims, taking whatever action they consider appropriate to alleviate losses. In this scenario, the implementation of compensatory schemes (e.g. financial assistance, tax exemptions) with a formal evaluation procedure should be considered by local authorities, to resolve conflict and improve the status of the deer population.

Severe problems with marsh deer appear to be restricted to a few small producers who have a high perception of damage and a fragile economic situation. However, three factors could potentially influence future interactions between people and marsh deer in this wetland. Firstly, the low number of producers reporting deer hunting should be interpreted with caution, as producers may have been reluctant to tell the truth for fear of being reported to the authorities for hunting illegally. Secondly, $69 \%$ of producers interviewed felt that the government should implement compensatory measures, even if they did not translate deer damage into economic losses. Thirdly, approximately half of interviewees considered it necessary to minimize damage caused by deer to prevent future economic impacts. This is a complex situation, as an expected outcome of the conservation actions currently in progress to conserve this marsh deer population is an increase in population size (J. Pereira, unpubl. data). A higher deer density as a result of conservation actions may trigger higher levels of damage and new claims for compensation by producers. However, the supposition that people respond proportionately to the level of damage experienced is erroneous, as even a small amount of damage can elicit a strong response (Knight, 2000; Dickman, 2010).

Although resolving the current problems would improve both the economic situation of local producers and their perceptions of marsh deer, negative attitudes often remain even after damage has been reduced (Dickman, 2010). Consequently, close monitoring of damage perception by forestry producers, and compensatory schemes to assist small producers, are necessary to adequately manage coexistence between producers and marsh deer.

\section{Acknowledgements}

We thank the forestry producers who responded to our questionnaire and provided valuable data. The Instituto Nacional de Tecnología Agropecuaria and Asociación para la Conservación y el Estudio de la Naturaleza partially funded this study. A. González, D. Olemberg, E. Villegas, R. Landó, J.M. García-Conde, F. Barzan, V. Casa, C. Iezzi and A. Donegana provided assistance or field support. M. Fisher and two anonymous reviewers provided helpful comments.

\section{Author contributions}

MEI collected, analysed and interpreted data, and drafted and revised the article. NGF conceived and designed the study, analysed and interpreted data, and revised the article. JAP conceived and designed the study, analysed and interpreted data, and drafted and revised the article.

\section{References}

Borodowski, E.D. \& SuÁrez, R.O. (2004) El cultivo de álamos y sauces: su historia en el Delta del Paraná. SAGPyA Forestal, 32, 5-13. Campbell-Smith, G., Simanjorang, H.V.P., Leader-Williams, N. \& Linkie, M. (2010) Local attitudes and perceptions toward crop-raiding by orangutans (Pongo abelii) and other nonhuman primates in northern Sumatra, Indonesia. American Journal of Primatology, 72, 866-876. 
Caruso, N., Luengos Vidal, E., Guerisoli, M. \& Lucherini, M. (2017) Carnivore occurrence: do interview-based surveys produce unreliable results? Oryx, 51, 240-245.

Conover, M.R. (1997) Monetary and intangible valuation of deer in the United States. Wildlife Society Bulletin, 25, 298-305.

Conover, M.R. (1998) Perceptions of American agricultural producers about wildlife on their farms and ranches. Wildlife Society Bulletin, 26, 597-604.

D’Alessio, S., Lartigau, B., Aprile, G., Herrera, P., Varela, D., Gagliardi, F. \& Mónaco, C. (2006) Distribución, abundancia relativa y acciones para la conservación del ciervo de los pantanos en el Bajo Delta del río Paraná. In Humedales Fluviales de América del Sur. Hacia un manejo sustentable (eds J. Peteán \& J. Cappato), pp. 129-153. Proteger Ediciones, Santa Fe, Argentina.

Dickman, A.J. (2010) Complexities of conflict: the importance of considering social factors for effectively resolving human-wildlife conflict. Animal Conservation, 13, 458-466.

Dressel, S., SAndström, C. \& Ericsson, G. (2015) A meta-analysis of studies on attitudes toward bears and wolves across Europe 1976-2012. Conservation Biology, 29, 565-574.

Duarte, J.M.B. \& González, S. (2010) Neotropical Cervidology: Biology and Medicine of Latin American Deer. Funep/IUCN, Jaboticabal, Brazil.

Duarte, J.M.B., Varela, D., Piovezan, U., Beccaceci, M.D. \& GARCIA, J.E. (2016) Blastocerus dichotomus. In The IUCN Red List of Threatened Species 2016: e.T2828A22160916. Http://dx.doi.org/10. 2305/IUCN.UK.2016-1.RLTS.T2828A22160916.en [accessed 2 January 2017].

Fracassi, N. \& Somma, D. (2010) Participatory Action Research Concerning the Landscape Use by a Native Cervid in a Wetland of the Plata Basin, Argentina. IUFRO Landscape Ecology International Conference, Bragança, Portugal.

Fracassi, N., Quintana, R.D., Pereira, J.A. \& Mujica, G. (2014) Estrategias de Conservación de la Biodiversidad en Plantaciones Forestales de Salicáceas del Bajo Delta del Paraná. Serie de publicaciones INTA, Buenos Aires, Argentina.

GiLL, R.M.A. (1992) A review of damage by mammals in north temperate forests: 1. Deer. Forestry, 65, 145-169.

Kandus, P. \& Malvárez, A.I. (2004) Vegetation patterns and change analysis in the lower delta islands of the Paraná River (Argentina). Wetlands, 24, 620-632.

Knight, J. (ed.) (200o) Natural Enemies: People-Wildlife Conflicts in Anthropological Perspective. Routledge, London, UK.

Lartigau, B., De Angelo, C., D’Alessio, S., Jiménez Pérez, I., Aprile, G., Aued, M.B. et al. (2012) Blastocerus dichotomus. In Libro Rojo de Mamíferos Amenazados de la Argentina (eds R. Ojeda, V. Chillo \& G.B. Díaz Isenrath), pp. 121-124. Sociedad Argentina para el Estudio de los Mamíferos, Mendoza, Argentina.

Márquez, A., Maldonado, J.E., González, S., Beccaceci, M.D., García, J.E. \& Duarte, J.M.B. (2006) Phylogeography and Pleistocene demographic history of the endangered marsh deer (Blastocerus dichotomus) from the Río de la Plata Basin. Conservation Genetics, 7, 563-575.
MCSHEA, W.J. (2012) Ecology and management of white-tailed deer in a changing world. Annals of the New York Academy of Sciences, 1249, 45-56.

Newing, H. (2011) Conducting Research in Conservation. Social Science Methods and Practice. Routledge, London, UK, \& New York, USA.

Olemberg, D.J. \& BarÁn, S. (2016) El mimbre en el Delta. Resultados del censo de productores mimbreros año 2015. INTA, Buenos Aires, Argentina.

Putman, R., Langbein, J., Green, P. \& Watson, P. (2011) Identifying threshold densities for wild deer in the UK above which negative impacts may occur. Mammal Review, 41, 175-196.

Richer, M., Ouellet, J., Lapointe, L., Crete, M. \& Huot, J. (2005) Impacts of white-tailed deer grazing in hay fields of southern Québec. Wildlife Society Bulletin, 33, 1274-1281.

Russell, F.L., Zippin, D.B. \& Fowler, N.L. (2001) Effects of white-tailed deer (Odocoileus virginianus) on plants, plant populations and communities: a review. The American Midland Naturalist, 146, 1-26.

Schonewald-Cox, C., Buechner, M., Sauvajot, R. \& Wilcox, B. A. (1992) Cross-boundary management between national parks and surrounding lands: a review and discussion. Environmental Management, 16, 273-282.

Siemer, W.E. \& Decker, D.J. (1996) Consideration of attitudes and values in deer management. In Living with Wildife: The Biology and Sociology of Suburban Deer and Beaver (eds A.N. Rowan \&

J.C. Weer), pp. 67-85. Tufts Center for Animals and Public Policy, North Grafton, USA.

TAKATSUKI, S. (2009) Effects of sika deer on vegetation in Japan: a review. Biological Conservation, 142, 1922-1929.

Varela, D. (2003) Distribución, Abundancia y Conservación del Ciervo de los Pantanos (Blastocerus dichotomus) en el bajo Delta del Río Paraná, Provincia de Buenos Aires, Argentina. BSc thesis. Universidad de Buenos Aires, Buenos Aires, Argentina.

VerCauteren, K.C., Lavelle, M.J. \& Hygnstrom, S. (2006) Fences and deer-damage management: a review of designs and efficacy. Wildlife Society Bulletin, 34, 191-200.

Ward, A.I., White, P.C., Smith, A. \& Critchley, C.H. (2004) Modelling the cost of roe deer browsing damage to forestry. Forest Ecology and Management, 191, 301-310.

WARD, J.S. \& WilLIAMS, S.C. (2010) Effectiveness of deer repellents in Connecticut. Human-Wildlife Interactions, 4, 56-66.

Weber, M. \& GonzÁlez, S. (2003) Latin American deer diversity and conservation: a review of status and distribution. Ecoscience, 10, 443-454.

\section{Biographical sketches}

M. EUGENia Iezzi's works focuses on mammal conservation in productive landscapes, and in particular the effects of forest management on mammal assemblages. NATALIA FraCASSI works on biodiversity conservation and sustainable production, focusing on ecosystem services in wetlands. JAVIER PEREIRA works on the population ecology, demography and conservation of mammals. 